\title{
The Counsellor and the Political Extensions of the Awareness of Ignorance in Proclus
}

\author{
Christos Terezis - Lydia Petridou \\ University of Patras, GR - Hellenic Open University, GR
}

TEREZIS, CH. - PETRIDOU, L.: The Counsellor and the Political Extensions of the Awareness of Ignorance in Proclus

Philosophica Critica, vol. 6, 2020, no. 2, ISSN 1339-8970, pp. 43-55.

In this study, we focus our attention on Proclus the Neoplatonist and the extract 177.22-180.26 from his commentary on Plato's Alcibiades I, where there is a thorough discussion on the qualities of a political counsellor. A purpose of ours is to investigate a part of an extremely systematic attempt in the context of Ancient Greek Philosophy to structure philosophy of that selfhood which is aware of its duty towards both itself and social body. In our elaboration, we make some references to Modern and Contemporary philosophy, since their representatives dealt systematically with this field.

Keywords: Proclus - Plato - Alcibiades - Counsellor - Awareness of ignorance - Formal logic

\section{Introduction}

Proclus the Neoplatonist (412-485) lived in a period of time during which philosophy in the sense of an independent rational mode of dialectical and reflective thinking was significantly restricted due to the development of theological and mystical tendencies. However, in the history of philosophy restriction does not necessarily mean underestimation. It means potential inclusion in a new perspective of approaching theoretical questions, existential issues and social procedures. That being said, Proclus wrote his works during one of the most critical periods in the history of philosophy, Ancient Greek thought, when man's effort to explain in an open perspective the existence, life, man, and his relation to the divine was remarkably restricted to a limited number of exponents and a small audience. 
Nevertheless, Proclus dealt with crucial philosophical questions, such as self-knowledge, which he considered the greatest existential accomplishment and the criterion for excellent collective behavior. In a basically different political and cultural environment - compared to that which is found in Antiquity - Proclus, as an authentic representative of the last period of the Platonic Academy, presented his theories by revealing his own scientific persona and the existential spirit of the fifth century, which was characterized by an intense interest in selfhood and in the way man could reach the divine. ${ }^{1}$

Therefore, focusing on Proclus' Commentary on the Platonic dialogue Alcibiades I, we can follow his effort - unprecedented in its systematic elaboration and intensity in Ancient Greek Philosophy - to structure the philosophy of self and person in an analytical, synthetic and interpretative way. Proclus actually developed the philosophy steadily while at the same time he followed the explicit and realistic direction of Greek thought. In this context, we believe that some references to modern and contemporary philosophy appear unavoidable, since their representatives approached the question of the thinking and acting subject thoroughly, and at least up to a point independently of the circumstances. Using these texts, one should definitely keep in mind that there is a historical distance between them, since Proclus, for instance, leaves no room to the possibility of interdependence of the personal subject and the ontological "being". Furthermore, he strongly suggests an a priori foundation of human consciousness, including the intellectual and moral one, on the divine gifts as well as the Platonic theory of recollection. ${ }^{2}$ However, the problems which people and societies face, together with the perspectives they form accordingly, are quite similar during history. The fact can be proved a good point to begin our comparison with.

In this study, we shall investigate the extract $177.22-180.26^{3}$ of this Commentary and we shall approach the topic of the awareness of ignorance. It forms the last section of Proclus's broader elaboration on the

$1 \quad$ See Saffrey (1990); Rappe (2000). These studies are extremely systematic and interpretative and make a thorough presentation of the spirituality of Late $\mathrm{Ne}$ oplatonism, referring mostly to topics that were elaborated by Plotinus and Iamblichus.

2 See for instance In Alc. 187.1-193.24.

3 This is an extract from Proclus' broader comment on the 106c.3-4 of Plato's

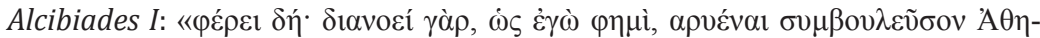

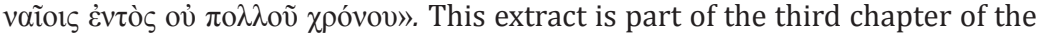
dialogue, in which the discussion between Socrates and Alcibiades develops and gradually focuses on Alcibiades' intention to become a political counsellor of the Athenians. 
question of selfhood ${ }^{4}$. The former sections were the following: the purpose and the general principles of catharsis, dialectics as a method of catharsis, the methodological steps of dialectics, the relation between dialectics and logic, the purpose of the definitions and the requirements of science. Proclus articulates this coherent reasoning by following the method of syllogisms, which also work transitionally in the structural support of a theory, and by combining realism (in the sense of accepting an objective-ontological basis of the general principles or "universals") with nominalism (in the sense of a thorough approach of the particulars), with the latter term proving through its exemplifications the former one. Therefore, he shows how relevant levels of a syllogism should be formed utilizing the methodological tools of synthesis (as the dialectic combination of his crucial points) and analysis (as a specified exposition of the details which are included in the topic under elaboration). Generally, we shall also attempt to prove that for Proclus the common good is the purpose of knowledge, a detail which in our view is performed by a counsellor. In this investigation, one should keep in mind that the concept of knowledge (as species) is placed in the concept of good (as genus), since, metaphysically speaking, in the philosopher's system the Good is axiologically and ontologically superior to the Intellect ${ }^{5}$ - a relationship that is also extended on the anthropological level.

\section{The Awareness of Ignorance and the Self-Evaluation of a Counsellor}

In the last part of the relevant argumentation, Proclus suggests that one should investigate another syllogism, which will arise from the elaboration of a new reflective - here as well as in the wider context - proposition. Therefore, he says that every thinker who studied the topic and came in touch with expert teachers to understand it scientifically is able to discuss the previous period of time in which he had realized - or at least was under the impression - that this topic was not a part of his knowledge. This is justified by the following crucial remark: those who are aware of their ignorance tend to come close to teachers-experts on the topic they study. To have an idea of what is the meaning of this difficult procedure, it is to be said that this is a clear axiological and intentional tendency of

$4 \quad$ This attempt starts in the extract 174.1, which opens an extensive and systematic elaboration of Proclus about the general catharsis of human existence and political presence through dialectics.

5 On this, one should see Proclus' reasoning developed in his six-volume treatise entitled Theol. Plat., in order to detect the complete priority of Good over all the metaphysical realities-categories, in which the Intellect is also included. The fifth volume is appropriate for our topic. 
the investigators, which, in a way, is obvious. Namely, they had actually realized that they were not able to free themselves from ignorance and gain knowledge on their own. Therefore, there is a period of time - even though a really short one - that comes before investigation and teaching, during which the would-be student who truly desires to make a thorough investigation draws the conclusion that he has no knowledge on the topics he intends to study and gain some good knowledge on. ${ }^{6}$ It should be mentioned however that Proclus does not mean complete ignorance; what he means is that the person who seeks scientific knowledge on a particular topic considers it as one of those that he systematically approaches or intends to approach in order to become a future expert as well. Due to the fact that he is not originally an expert on the details of the topic, that is to say, he does not really know the terms in which it is structured, he decides to transform his own deficient status and become an investigator and expert. For Proclus, the axiological distinction between the two time points in relation to degree and validity of their knowledge holds true for everybody; or, else, it is a procedure everyone experiences and it results from their own conclusions. Otherwise, they would not be investigators, that is to say, they would not be internal mediators of their own transition from the former state of ignorance or ambiguity to the following level of knowledge.

It is quite obvious, however, that the transition from ambiguity to the valid scientific knowledge requires the thinking subject, who is not yet scientifically well-trained and, due to having little information, has only a non-structured empirical knowledge with no syllogistic continuity, to have access to a thorough understanding of things. That is, he is now in the state of opinion. Or, at least, he possesses information that might cognitively activate him, an aspect that is compatible with what Proclus has already mentioned about the active and passive knowledge, with the latter functioning in terms of repetition. ${ }^{7}$ Active knowledge is quite different from the already pre-existing knowledge or, at least, adds something new, depending on the condition of the thinking subject who decides to accomplish the cognitive result that it has defined as goal. So, following the

6 See In Alc. 177.22-178.7. On the concept of self-knowledge in Socrates, see for instance (Guthrie 1971, 147-152). In our view, exactly because we are speaking about self-knowledge, Proclus's reasoning becomes - at least indirectly an exhortation, which, in a second level, turns into a principle. So, it does not just analyze or describe. In the text before this extract, he has proved that this process requires a thorough existential catharsis and a readiness for accepting something new. Cf. In Alc. 174.1-175.18. Therefore, the epistemological procedures exceed their field.

7 See In Alc. 175.19-176.21. 
general context of this passage, one could say that all developing investigators possess a priori knowledge, but only few of them are aware of this. In addition, in order to have access to it, both objective and subjective factors are required. The transition from the first state to the next one - or the recollection of a priori - is not an automatic process; it requires a broad consciousness with respect to the internal intellectual procedures and the relations with the objects to which they refer. This is the greatest point of Proclus's views about education and theory which are closely related to the theory of recollection which is analyzed in the Plato's Meno, Phaido and Phaedrus ${ }^{8}$, which, by extension, introduce the purpose of the pedagogical planning. Mutantis mutandis, we believe that the Neoplatonist philosopher would agree with the following points of J. Habermas about the position of theory in modern times:

\begin{abstract}
"On the other hand, however, they have abandoned the connection of theoria and kosmos, of mimesis and bios theoretikos that was assumed from Plato through Husserl. What was once supposed to comprise the practical efficacy of theory has now fallen prey to methodological prohibitions. The conception of theory as a process of cultivation of the person has become apocryphal. Today it appears to us that the mimetic conformity of the soul to the proportions of the universe, which seemed accessible to contemplation, had only taken theoretical knowledge into the service of the internalization of norms and thus estranged it from its legitimate task" (Habermas 1972, 304).
\end{abstract}

Extending the above, we could raise the following question: What was actually Proclus's intention? That if an investigator understands his ignorance, one actually comes to realize that at a specific time point he was not activated in such a way so as to conceive theoretically the world around him in his own cognitive terms (these would be the a priori ontological ones). Coming to know oneself, one actually discovers an appropriate beginning to be reconstructed with theoretical precision and to put the external world into categories, in the sense that he becomes able to explain the relation between world and its metaphysical demiurgic archetypes; therefore, he becomes able to understand how necessary is to use a new method to overcome simple sensible empiricism. Therefore, according to Proclus, speaking of the relation between active and passive knowledge, one could say that the sensible world or, else, the world of representations, because of the stimuli provided, puts human mind into action, by utilizing its own, actually original, principles, which exist before the

8 See for instance Brès $(1973,148-155,159-173,243-258)$. 
cognitive projections, to understand it. Obviously, these principles are not automatically revealed; they require systematic procedures that involve self-knowledge, until one gets to really know himself.

Proclus, focusing as usual on a specific subject matter, applies the above in the case of how a counsellor is scientifically formed and how he acts. He says that a) if a good counsellor acquires knowledge on the subjects for which he is a counsellor, either by investigating or by being taught by others and b) if generally there is a specific time for everyone who investigates or is being educated during which he gets to realize the degree of his ignorance, the same temporal distinction and change of quality appear by implication and exemplification here as well. Specifically, it is necessarily accepted that a good counsellor is able to draw some conclusions about a particular time of the past, during which he was aware or at least he had an idea of his insufficiency to counsel. ${ }^{9}$ Placing his point of view in a clearly epistemological context, we could argue that the possibility of a priori active knowledge, or possibility of an inherent complete conscious possession of a complete theoretical - either investigative or scientific - knowledge, are totally excluded in the first place. Therefore, taking into account that extreme idealism is not an option (in the sense that being is theoretically defined by the categories of thought $)^{10}$, the whole idea turns out to be a transition from false knowledge or complete ignorance - which has been identified as such - to thorough knowledge that is gained after the activation or utilization of internal or external factors proper for such an accomplishment. This is where we can also place the inherent capability for knowledge and the advantages of teaching. Proclus, thinking completely logically, comes to the conclusion that the above are three separate arguments that have been formed by the first two propositions of the whole reasoning, which actually show how the principle of the demonstrative succession through coherent functions works. ${ }^{11}$ This is a transition that

$9 \quad$ See In Alc. 178.8-12. About how Socrates understands the right political attitude, see for instance Santas (1999, 57-180), where the way in which the Athenian dialectician defines the relation with God is also analyzed.

10 On the concept of realism and a comparison to that of idealism, see Nagel (1986, 90-98).

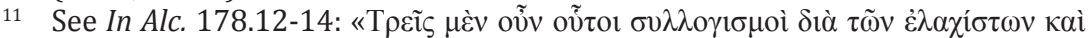

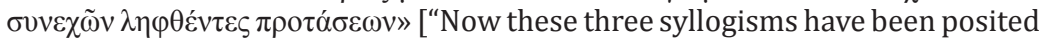
by means of the fewest possible consecutive premises" (O'Neill, 118)]. Segonds $(2003,389)$, says the following: "En effet, les trois syllogismes qui précèdent ne reposent que sur quatre propositions, comme le montre Olympiodore, 67.20-68.3, à savoir: majeure et mineure du premier syllogisme (p. 176.12-21; 21-28); majeure du deuxième (p. 177.12-17); majeure du troisième (p. 177.24178.7). La conclusion du premier syllogisme sert de mineure au deuxième et 
brings a preexisting mental capability in a dialectical and critical relation with itself, by means of a scientific activity caused for many reasons. So, we are facing a gradual process, the purpose of which is to accomplish specific theoretical goals.

On this basis, the philosopher contends that if one intends to compose particular arguments in order to reach a more complex one, one has to follow a synthetic schema, which is neither formed by autonomous intentions nor structured by additional judgements. And - at least according to what has been said to this point - this kind of structure cannot be defined only a posteriori. Proclus explains this as follows: this is a final schema formed by the arguments of the first schema. Those were only introductory and needed to be exemplified. In his view, this succession - the development of which could be described as analytical - relies on the fact that all that is to come into existence is already included - in the sense of primordial reasons - in the first schema of universal affirmation. ${ }^{12}$ Obviously, for Proclus the first schema is identified with the first phase of a syllogism, where his judgments on the counsellor and scientist were expressed in positive attributes independent from empirical information

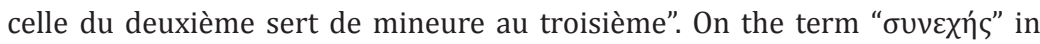

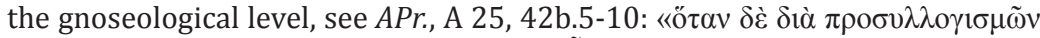

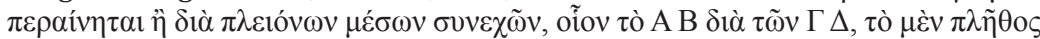

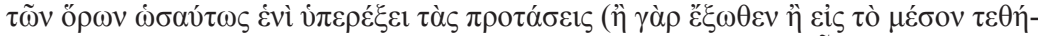

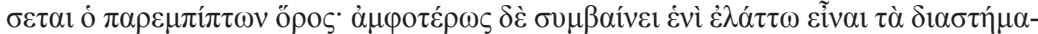

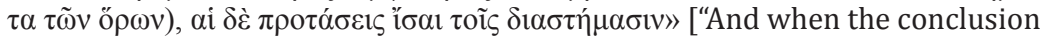
is reached by means of prior deductions or several continuous middle terms (for instance if premise $\mathrm{AB}$ is concluded through terms $\mathrm{C}$ and $\mathrm{D}$ ), then the number of terms will likewise exceed the premises by one (for the term inserted will be put either outside or in the middle; but in both ways it results that the intervals are one fewer than the terms, and the premises are equal to the intervals)"(Smith, 1989, 40)]

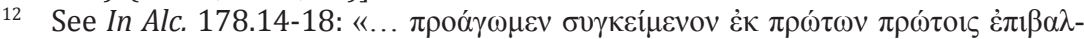
$\lambda$ óv $\tau \omega v . .$.$\rangle ["let us pronounce it thus in due order according to the so-called$ composite form, made up of firsts overlapping firsts" (O'Neill 1971,118)]. Con-

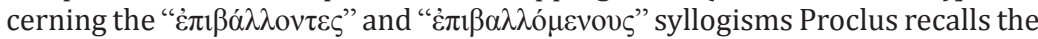
relevant Stoic tradition. See Alexander of Aphrodisias, in APr. 283.17-24: «Oi

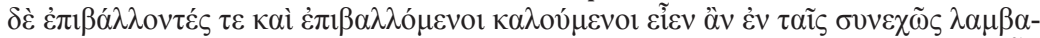

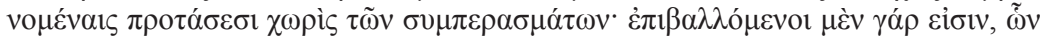

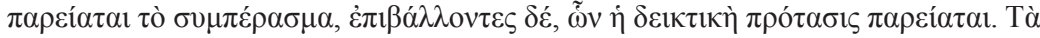

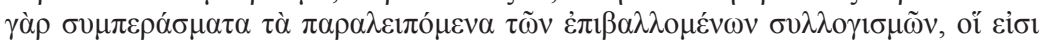

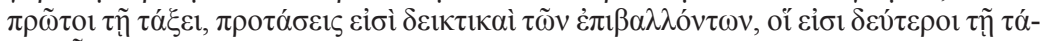

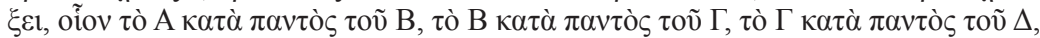

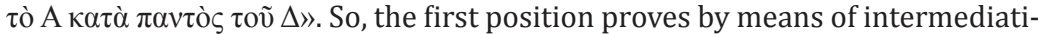
ons and places into categories anything that is to be followed to the end of the syllogism, that is to say, the conclusion that will be drawn from the succession and the internal connection of the former propositions. 
and conclusions. Moreover, everything to be specified there was placed in the form of programmatic validating schemas. Inevitably, the entire epistemological and logical process is based on composition and not on simple addition. The first specification works as the principle and source of a somewhat teleological intention, which, since it deals with what has been already elaborated, obviously unfolds in a spiral mode.

\section{To an Approach According to Formal Logic}

What is the main conclusion? Proclus leads us to the following, which relate with the formal Logic: The individual propositions of a long syllogism follow a specific order whereas they also relate to each other. This interactivity occurs not only because every proposition has a term which structures and justifies how it works but also because it will be associated with the others. In this way, a syllogism can be integrally formed, since it is gradually extended by the addition of each proposition. All these take place from a final composite conclusion that exceeds every particular proposition, even though it is permanently defined and made known either by the content of the interactivity between individual propositions or by their mutual confirmation. In addition, this result is an expression of the common and universal. So, the way in which the common or universal concepts define the individual ones - in which they are found and applied - constitutes a general epistemological example to follow, so that a valid conclusion can arise in each and every syllogistic implementation. That is to say, it is a matter of logical principles, the use of which can change even without any change in the original regulatory context, which can be generally used as a reasoning and structural schema. Adjustments are necessary because of the multiple forms of reality, which is the necessary condition of forming any syllogisms. In other words, a particular content becomes valid as expressed in a particular form, without ending its connection - under its own terms and conditions - to the appropriate principle, a special detail it reflects on with an extreme logical accuracy. Therefore, it follows that the change of the content is not related to the principle itself but to the circumstances in which it works. Its application, not only in methodological terms, is adjusted to anything it faces. With these adjustments it reveals its capacity to describe in syllogism all the forms that relate to its general content. It thus becomes clear that nominalism - in the sense that it describes something particular - is not only utilized, but also, through the exemplifications, proves the precision of the cognitive products, which reveal a special correspondence with the general principle, of which they are part of, as has already been proven. 
On a Hegelian approach of the matter discussed, E. B. Ilyenkov adds the following:

\begin{abstract}
"The central concept of Hegel's logic was therefore the concrete-universal: he brilliantly illustrated its distinction from the simple, abstract universality of the sphere of notions in his famous pamphlet Wer denkt abstrakt? (Who thinks abstractly?). To think abstractly meant to be enslaved by the force of current catchphrases and clichés, of one-sided, empty definitions; meant to see in real, sensuously intuited things only an insignificant part of their real content, only those of their determinations that were already 'jelled' in consciousness and functioned there as ready-made stereotypes. Hence the 'magic force' of current catchphrases and expressions, which fence reality off from the reach of a thinking person instead of serving as the form of its expression. In this last interpretation logic finally became a real logic of understanding of unity in variety, and not a schema for manipulating readymade ideas and notions; the logic of critical and self-critical thought and not a means of the uncritical classification and pedantic, schematic presentation of existing ideas". (1977, 118-119).
\end{abstract}

The fact that Proclus does not remain in an abstractive formulation of the concepts is clear in all of his works. The most typical example is perhaps the second book of his treatise entitled Theologia Platonica, where he approaches by following an ascending course to the highest levels of metaphysics adopting the principles of formal Logic, after having associated them with principles of epistemology ${ }^{13}$. Generally speaking, one could argue that through epistemology or logic, he reveals the true - or, according to the context, logical - content of the individual objects. Proclus would definitely agree with all that was said about Hegel above, provided that the natural world is a true reflection of the metaphysical archetypes, which work as an expression of the divine unity within the multiple forms of the world of becoming. The Neoplatonist philosopher founds every ontological and epistemological logic elaboration on the divine revelation and on the resulting specialized theophanies. His Commentary on the Timaeus confirms this. ${ }^{14}$

By following an opposite course, namely, from the conclusion to the direct and indirect syllogistic causes from which it was drawn, Proclus concludes in short the following: i) a good counsellor knows in depth the

13 See mostly II, 3.6-23-12, where Proclus attempts to include in syllogistic schemata even the One-Good.

14 See for instance the Neoplatonist philosopher's comments on Ti., 381.26296.25, where Proclus attempts in a fascinating syllogism to prove that Plato does not adopt ontological dualism but ontological monism. 
subjects on which he counsels. ii) The person who has a thorough knowledge of the subjects on which he counsels, has acquired this knowledge either by learning or discovery. iii) The person who attended a teacher or looked on its own for some scientific knowledge had realized that there was a specific time at which he knew nothing about the subjects on which he was to counsel its fellow-citizens. Synthesizing the above, Proclus says that it is necessary that the two minor premises -the first ones- would be combined with the two factors that compose them as well as everything else in general. For instance, one could contend that scientific knowledge is necessarily successively connected with the awareness of ignorance, the learning-discovery process and the counselling which is addressed to his fellow men. So, it is a state which someone reaches when he composes in integral terms knowledge with practice, or, else, theoretical reason with the practical one. Approaching the opposite way, the conclusion would be the following: since Alcibiades neither sought for nor was taught by a teacher anything appropriate for his purpose, he is not a good counsellor. In this example, the premises of the syllogism should be combined in a similar way with those above, but in a negative sense. The conclusion is as follows: since Alcibiades - as it becomes apparent from the above passive conditions - is not able to express an opinion about the fact that he had actually realized his ignorance at a specific moment in the past, the conclusion is that he cannot be a good counsellor. ${ }^{15}$

Thus, it is quite necessary for a man to be aware of both his knowledge and ignorance, in order to receive an attribute or to be called after a property that is related to the responsibilities that he will undertake which are fed by a sufficient scientific reason. The whole argument relies on regulatory principles internally justified, which define what should be done as well as any kind of relation that is to be developed. This requirement also ensures that the thinking subject is able to improve gradually and

15 See In Alc. 178.18-30. Segonds $(2003,390)$ points out the following on Pro-

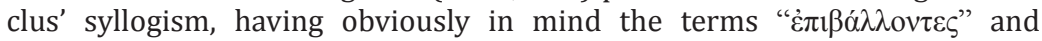

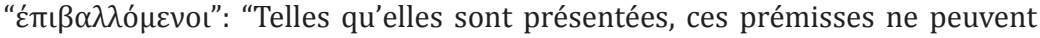
être appelées un syllogisme que dans un sens très lâche, comme le fait Proclus (178.24): il manque tout simplement la conclusion. En fait, il s'agit d'un «prosyllogisme» (Ol., 68.3), qui devrait avoir pour conclusion: «Tout bon conseiller peut donc dire un temps où il pensait ne pas connaître les matières sur lesquelles il donne des conseils. Maintenant à l'aide des prémisses du prosyllogisme prises pour majeures, Proclus va former des syllogismes en Baroco (A =

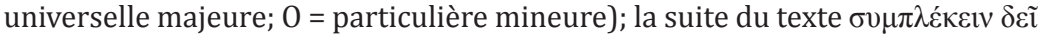
$\kappa \tau \varepsilon ́$ n'est pas absolument claire. Je comprends qu'il faut successivement lier, à chacune des propositions aussi bien qu'a toutes prises ensemble, des mineures pour obtenir d'autres syllogismes qui réfutent Alcibiade". 
dynamically his mental skills, regardless of whether this is about acquiring or recovering knowledge. And since all these are related to the political counsellor, we would add that they are considered to be necessarily institutional or, at least, deliberative suggestions in the context of a democracy, the purpose of which, as an institutional liberalism that follows particular principles, is to activate the citizens to participate intentionally to collective actions.

Furthermore, we should not ignore the following conclusive extension about the counsellor and scientist: it is better for someone to be a good - or, else, capable of practicing and providing - counsellor than being just someone with knowledge that is kept in the very inner centers of his consciousness. Therefore, axiologically it is more important that scientific knowledge be developed into an educational and social good. From the metaphysical point of view, Proclus contends that knowledge reveals the participation in the Intellect, while goodness directs to a superior condition that does not need to reach a higher ontological level.

\section{Extensions}

On the basis of what was investigated, the following extensions arise: the whole elaboration may be included in what is defined as reflection, which seems to be considered by Proclus as the greatest anthropological goal, since by its completion he reestablishes truth as an inherent and a priori property of human consciousness. Therefore, reflection is almost identified with self-examination. There are three successive complementary aspects in which Proclus presents reflection: first of all, as a necessity for the thinking subject to investigate itself, in order the appropriate time and by reconstructing its existence to discover the degree, quality and practical projection of its cognitive capacity. This step will constitute the beginning for any other necessary detection. Secondly, as a procedure that reveals the human boundaries in investigation, in order to understand what its gnoseological goal should realistically be. The case here is about interpretation, not only in the sense of a transformation of what has been already found but also as a formation of a new duty status from the methodological point of view. Third, as an analysis of the scientific knowledge as regards the content and methods in which it develops or is discovered by human consciousness. This approach is necessary since man will be able to assimilate the principles to be followed, as a kind of regularity for establishing an authentic and firm relation with the truth, as a possibly precise representation of the true being. A flexible formal Logic comes here to the fore. Through his pedagogical analyses and proposals Proclus attempts to 
structure a being that would be the sensible-historical expression of the metaphysical perfection. Considering the relation between man and the natural world he identifies the risk of a potential loss of the truly authentic, although he does not doubt for the scientific contribution - at least in the first step - of the sense representations as challenges for an upward course.

The next challenging question, however, is the following: under what terms and conditions does philosophy contribute to the interpretation and transformation of the social life and the political institutions? Although social and political philosophy were not his main fields of interest, Proclus dealt with them in his works, for instance in his Commentary on Plato's Republic. In his comments on Alcibiades I, he attempted to show the necessary requirements which a subject should fulfil to develop an appropriate social and political attitude based on the way in which the unchanged metaphysical foundations will turn into regulatory principles to be followed for both thought and action in the sensible world. In his view, the whole idea exceeds sensible world and is about how human subjects will recover the truth through philosophical reflection following stable principles which recover memory. The circular argument arises, which requires the a priori understanding - or, more correctly, pre-understanding - of what will be placed a posteriori into conceptual categories, where beginning and end are identical. The next thing to be investigated is how a formed subject will be engaged to the social and political actions. The "good counsellor" is the most capable person to do that, since he is the active consciousness of the political system. So, could the "good counsellor" be the basis for transforming philosophy into an epistemology that is founded on social terms, which are ontologically defined? We would contend that it is not a coincidence that in his Commentary Proclus considers this counsellor to be the historical presence of an authentic image of the divine counsellor, the "forefather" of the choices to be made for the realization of both the personal ethics and general anthropological teleology.

\section{References}

\section{Sources:}

ARISTOTLE (1989): Prior Analytics. R. Smith (trans.). Indianapolis: Hackett. PROCLUS (1971): Alcibiades I. W. O'Neill (trans.). The Hague: Springer. PROCLUS (2003): Sur la Premier Alcibiade de Platon, II. A. Ph. Segonds (transl.). Paris: Les Belles Lettres. 


\section{Studies:}

BRÈS, Y. (1973): La Psychologie de Platon. Paris: P.U.F.

GUTHRIE, W. K. C. (1971): Socrates. Cambridge: Cambridge University Press.

HABERMAS, J. (1972): Knowledge and Human Interests. J. J. Shapiro (trans.). Boston: Beacon Press.

ILYENKOV, E. B. (1977): Dialectical Logic. H. Campbell Creighton (trans.).

NAGEL, T. (1986): The view from nowhere. New York - Oxford: Oxford University Press.

RAPPE, S. (2000): Reading Neoplatonism: Non-discursive Thinking in the Texts of Plotinus, Proclus, and Damascius. Michigan: University of Michigan.

SAFFREY, H. D. (1990): Recherches sur le Néoplatonisme après Plotin. Paris: J. Vrin.

SANTAS, G. X. (1999): Socrates: The Arguments of the Philosophers. London - New York: Routledge.

\section{Prof. Christos Terezis,}

Department of Philosophy

University of Patras

26500

Rion-Patras

Greece

terezis@upatras.gr

\section{Lydia Petridou, PhD.}

Hellenic Open University

Fanariou 25

65404 Kavala

Greece

petridou.lydia@ac.eap.gr 